\title{
What Factors Drive Analyst Forecasts?
}

\section{Citation}

Groysberg, Boris, Paul Healy, Nitin Nohria, and George Serafeim. "What Factors Drive Analyst Forecasts?" Financial Analysts Journal 67, no. 4 (July-August 2011).

\section{Published Version}

http://dx.doi.org/10.2469/faj.v67.n4.4

\section{Permanent link}

http://nrs.harvard.edu/urn-3:HUL.InstRepos:13426861

\section{Terms of Use}

This article was downloaded from Harvard University's DASH repository, and is made available under the terms and conditions applicable to Open Access Policy Articles, as set forth at http:// nrs.harvard.edu/urn-3:HUL.InstRepos:dash.current.terms-of-use\#OAP

\section{Share Your Story}

The Harvard community has made this article openly available.

Please share how this access benefits you. Submit a story.

\section{Accessibility}




\section{What Factors Drive Analyst Forecasts?}

Boris Groysberg

Boris Groysberg is professor of business administration at Harvard Business School, Boston.

Paul Healy

Paul Healy is professor of business administration at Harvard Business School, Boston.

Nitin Nohria

Nitin Nohria is professor of business administration at Harvard Business School, Boston.

George Serafeim

George Serafeim is professor of business administration at Harvard Business School, Boston.

Using survey data to judge how analyst forecasts are related to evaluations of companies' industry competitiveness, strategic choices, and internal capabilities, the authors found that analyst forecasts are associated with many of the factors that money managers rate as important in their assessments of analyst contributions. They also found wide variation in ratings consistency across variables among analysts covering the same company. On average, consistency is higher for sell-side analysts than for buyside analysts.

Although extensive research has been conducted on analysts' earnings forecasts and recommendations (see Bradshaw 2010; Schipper 1991), relatively little has been written about the factors that underlie them. ${ }^{1}$ In our study, we examined which industry, leadership, and company factors are related to analysts' forecasts of financial and stock performance. We also examined whether analysts covering the same company make consistent assessments of its industry, leadership, and company capabilities.

\section{Prior Research}

\footnotetext{
${ }^{1}$ Previous academic studies have shown that analysts incorporate public disclosures on company risk, competitive changes, competitive positioning, and management into their analyses (see Previts, Bricker, Robinson, and Young 1994; Rogers and Grant 1997; Ramnath, Rock, and Shane 2008). In addition, Asquith, Mikhail, and Au (2005) found that stock prices react to qualitative information in analysts' reports. What remains unclear from these studies is which factors are most important for analysts' overall assessments of companies' expected future performance.
} 
Prior research suggests that three primary factors drive company performance: industry characteristics, company characteristics, and leadership characteristics. Wasserman, Nohria, and Anand (2010) found that industry characteristics accounted for 15.5 percent of the variation in company performance, company characteristics 32.8 percent, and leadership characteristics 13.5 percent.

\section{Industry Characteristics.}

Porter (1985) and McGahan and Porter (1997) demonstrated that a company's performance is influenced by the growth and structure of its industry. A growing industry can lift all boats. In addition, an industry's attractiveness is affected by rivalry among its existing companies, entry barriers faced by potential competitors, the power of customers and suppliers, and the threat of substitute products or services.

\section{Company Characteristics.}

Porter (1980) showed that companies within an industry earn differential returns if they develop a distinct competitive advantage, either by having a lower cost structure than their competitors or by offering a superior product/service.

Others argue that simply developing a strategy is not enough. To be successful, companies must also be able to execute their strategies (Galbraith and Kazanjian 1986; Kaplan and Norton 2008; Joyce, Nohria, and Robertson 2003), communicate their strategies effectively (Bower 1970), and adjust their strategies on the basis of competitors' actions (Brandenburger and Nalebuff 1996). In addition, strategy execution and company performance are affected by organizational culture (Kotter and Heskett 1992; Huselid 1995; Joyce, Nohria, and Robertson 2003).

Finally, ever since Schumpeter (1942), management theorists have argued that innovative companies are consistently more successful than noninnovative companies (Henderson and Clark 1990; Christensen 1997; 
Utterback 1994; Mansfield 1995; Mowery and Rosenberg 1998; Tushman and O'Reilly 2002).

\section{Leadership Characteristics.}

Management quality is frequently cited as a key determinant of company performance, both through its effect on decision-making and execution (Kotter 1990; Hackman and Wageman 1995; Kaplan, Klebanov, and Sorensen 2008; Bass 2008; Finkelstein, Hambrick, and Cannella 2009) and through the promotion of strong governance (Carter and Lorsch 2004).

\section{Survey and Sample}

As we have seen, prior research suggests that in forecasting a company's performance, analysts are likely to consider such factors as the growth and competitiveness of its industry, its strategic positioning, execution of strategy, innovation, leadership, culture, and financial resources. To examine which of these factors are related to analyst forecasts, we designed a survey that asked analysts to provide forecasts of revenue and earnings growth, gross margins, and stock price appreciation, as well as ratings on the factors, for up to three companies that they covered. The survey questions are presented in Exhibit 1.

We identified our survey sample by searching databases maintained by the Dow Jones News Service, Institutional Investor, LexisNexis, the National Association of Securities Dealers, Nelson's Directories, and Yahoo! Finance for the names and addresses of analysts who worked at investment banks, brokerage firms, research boutiques, and money management firms in the United States, Europe, Asia, and Latin America. From these sources, we constructed a list of 5,090 analysts, whom we invited to participate in our online survey during two periods: December 2004-April 2005 and March 2006July 2006.

Analysts were first asked to identify the country/region and major industry that they covered (from a list provided in the survey) and then to 
select up to three companies from that region/industry with which they were most familiar (again, from a list provided in the survey). Only companies listed on the major stock indices were included. For example, in the United States, only companies listed on the S\&P 500 Index were included.

Analysts were asked to complete the survey questions for each company they selected by using a Likert (i.e., unidimensional) scale of 1 to 5 , a commonly used and widely recommended approach for rating beliefs and attitudes. For Questions 1-5, which asked analysts to rate an industry without any benchmark, 1 signified a rating of "highly unlikely," 2 "somewhat unlikely," 3 "neither likely nor unlikely," 4 "somewhat likely," and 5 "highly likely." For example, Question 2 asked, "In the next 12 months, how likely [is] the following in each company's business environment: Greater price competition?" A rating of 1 indicated that the analyst believed that increased price competition in the industry in the next 12 months was "highly unlikely," whereas a 5 indicated the belief that it was "highly likely."

For Questions 6-20, which requested a comparison of companies with their peers, 1 signified a rating of "significantly less," 2 "somewhat less," 3 "the same," 4 "somewhat more," and 5 "significantly more." For example, Question 10 asked, "Relative to its peers, does the company have a clear and wellcommunicated strategy?" A rating of 1 indicated that the analyst believed the company's strategy was "significantly less" clear than that of its peers, whereas a 5 indicated that the company's strategy was viewed as "significantly more" clear than that of its peers.

We received survey responses from 967 analysts, representing a 19 percent response rate. ${ }^{2}$ Participants provided 2,179 usable survey responses for 837 companies. ${ }^{3}$ Our sample included 1,484 observations from 638 sell-

\footnotetext{
${ }^{2}$ Many studies have reported similar response rates for external online surveys. For example, comparing internet and mail survey response rates, Kaplowitz, Hadlock, and Levine (2004) documented a 20 percent response rate for e-mail-only surveys.

${ }^{3}$ We were unable to use 774 responses because analysts did not complete all the questions needed to construct the independent and dependent variables of interest.
} 
side analysts and 643 observations from 329 buy-side analysts. ${ }^{4}$ Table 1 provides a summary of the sample analysts and companies by region and industry; 40 percent of the responding analysts were from the United States, 27 percent were from Europe, 25 percent from Asia Pacific, and 8 percent from Latin America. Key covered industries included finance (22 percent), noncyclical consumer goods (14 percent), cyclical services (13 percent), and information technology (11 percent).

We conducted several tests to assess the integrity of the survey data. We used the first one, a Likert summated rating test, to determine whether sample analysts systematically selected companies for which they had either positive or negative opinions. If an analyst responded with 1 to all 20 questions, the summated rating score was 20; a response of 5 to every question generated a summated score of $100(5 \times 20)$. For the overall sample, the average summated score was 69 , indicating that analysts selected companies that they expected to perform well, which is consistent with prior research (see Dugar and Nathan 1995; McNichols and O’Brien 1997; Lin and McNichols 1998; Cowen, Groysberg, and Healy 2006). Summed scores did not differ significantly for analysts from different geographic regions or industries or across the two surveys.

In addition, we examined the data to assess whether the ratings made sense for certain prominent companies. Analysts rated Wal-Mart Stores, Target Corporation, and Southwest Airlines as having a low-price strategy. Apple was rated low on low prices and high on innovation, whereas Dell and Gateway were rated high on low prices and low on innovation. Furthermore, companies that followed the same strategy differed predictably along other dimensions. For example, Dell was among the highest-ranked companies on execution, whereas Gateway was among those ranked lowest.

${ }^{4}$ For 52 observations, we were unable to determine whether the analyst worked for the buy side or the sell side. 
Table 2 reports the response frequencies for the survey variables that we used in our study. For almost all questions, analysts consistently favored the top three ratings. As a result, the median rating was 4 (out of 5) for 11 of the 16 variables and 3 for the remainder. Variables with high frequencies of 4 and 5 included strategy communication, strategy execution, management quality, understanding of competitors, forecasted industry growth, superior products/services strategy, and balance sheet strength. Variables with relatively high frequencies of 1 and 2 included all the forecasted financial and stock performance metrics, strategy communication, high performance standards, low-price strategy, and industry competitiveness.

Table 3 shows simple pairwise Pearson correlations between the survey variables. Not surprisingly, the correlations are sizable and statistically significant across many variables. Ratings of the various measures of companies' forecasted performance (revenue growth, gross margins, earnings growth, and stock price appreciation) are highly correlated. Ratings of such qualitative capabilities as management quality, strategy execution, innovation, governance, strategy communication, culture, incentives, and financial strength are also highly correlated.

In contrast, the industry factor and competitive positioning correlations vary in magnitude. Although ratings of industry competitiveness and company price competitiveness are not highly correlated with any of the other survey variables, ratings of forecasted industry growth and superior product/service strategy have correlations that are typically significant both statistically and economically.

\section{Tests and Results}

We report our results of tests conducted to assess which factors affect analyst forecasts and whether there is consistency in factor ratings across analysts who cover the same company. 


\section{Factors Associated with Analyst Forecasts.}

We used our first test to estimate the relationship between analysts' ratings of company revenue growth, gross margin, earnings growth, and stock price appreciation forecasts and their ratings of the industry, strategy, leadership, and financial resources variables. Given the ordinal nature of the dependent variables, we estimated the relationship between forecast performance and the independent variables by using an ordered probit model (see Campbell, Lo, and MacKinlay 1997).

To assess how the surveyed factors affect forecasted performance relative to actual current performance, we estimated models that include and exclude current performance for each forecast variable. ${ }^{5}$ Actual revenue growth is the percentage change in revenues for the current fiscal year. Gross margin is the current year's gross profit as a percentage of sales. Earnings growth is defined as the change in earnings per share for the year deflated by the stock price at the beginning of the year. Earnings changes are deflated by stock price, rather than by prior-year earnings, because some companies have small or negative prior-year earnings, which leads to earnings growth that is exploding, undefined, or misleading. Finally, stock price appreciation is the percentage change in stock price for the latest fiscal year.

Our tests included time, geographic region, and industry fixed effects to control for systematic differences in companies and analysts across these dimensions. To control for serial correlation within companies, we clustered standard errors at the company level.

Table 4 reports the estimated coefficients for the ordered probit models that include and exclude current performance. Not surprisingly, current performance is typically related to the forecast ratings. More importantly,

\footnotetext{
5Prior studies have documented that the sign and magnitude of forecast revisions are positively associated with the sign and magnitude of past stock returns (Givoly and Lakonishok 1979; Lys and Sohn 1990; Abarbanell 1991).
} 
estimates for the other variables are generally unaffected by the inclusion or exclusion of this control. 6

The most important explanatory variable across all models is forecasted industry growth. The estimates for this variable are both statistically and economically significant. A two-point Likert scale increase in an analyst's rating of a company's industry growth increases the probability that forecasted revenue growth is rated 4 by 13.4 percentage points (pps) (from 42.9 percent to 56.3 percent) and almost doubles the probability of a rating of 5 (from 10.3 percent to 20.5 percent). ${ }^{7}$ Comparable increases in industry growth ratings also increase the probability that analysts issue ratings of 4 or 5 for gross margins, earnings growth, and stock price appreciation. The magnitudes (ranging from 6.3 percent to $9.6 \mathrm{pps})$, however, are somewhat lower than those for revenue growth.

The next two most important explanatory variables are quality of top management and ability to execute strategy. Both are statistically and economically significant across all four forecast models. For quality of top management, a two-point Likert scale increase in an analyst's rating of a company increases the likelihood that the analyst issued a forecast rating of 4 by $6.1 \mathrm{pps}$ for revenue growth, $6.2 \mathrm{pps}$ for gross margins, $7.5 \mathrm{pps}$ for earnings growth, and $7.3 \mathrm{pps}$ for stock appreciation. Comparable effects for strategy execution are 8 pps for revenue growth, 6 pps for gross margins, 6 pps for earnings growth, and 3.7 pps for stock appreciation.

The estimates for performance-driven culture and industry competitiveness are significant for models of forecasted financial performance (revenue growth, earnings growth, and gross margins) but not for stock price appreciation. The estimates imply that increasing an analyst's rating of a

\footnotetext{
${ }^{6}$ Using an alternative approach, we estimated the models separately for companies that analysts rated as having clear strategies (based on price or product/service differentiation). These findings are similar to those reported in Table 4.

${ }^{7}$ Because we used an ordered probit as the specification, a different marginal effect is associated with each level of the dependent variable.
} 
company's performance-driven culture by two points increases the likelihood that the analyst gives the company's future revenue growth, gross margins, and earnings growth a rating of 4 by $6.4 \mathrm{pps}, 7.1 \mathrm{pps}$, and $4.2 \mathrm{pps}$, respectively. Comparable effects for industry competitiveness are $-5.5 \mathrm{pps},-4.8$ pps, and -4.3 pps, which suggests that analysts are less optimistic about the prospects of companies in industries where supplier power, price competition, new products, and entry are expected to increase.

Estimates for ratings on innovation and low-price strategy are also significant for the three growth forecast models (revenues, earnings, and stock prices). Increasing an analyst's rating of a company's low-price variable by two points increases the likelihood of a forecast rating of 4 by 4.8 pps for revenue growth, $3.6 \mathrm{pps}$ for earnings growth, and $4.3 \mathrm{pps}$ for stock price growth. The effects for innovation are similar in magnitude. ${ }^{8}$

The economic importance of the industry growth/competitiveness and company capability variables for analyst forecasts is consistent with money manager feedback on sell-side analysts. In ratings of sell-side analyst research, money managers consistently rank analysts' assessments of industry dynamics, companies' strategic positioning, and companies' internal capabilities as among their most important contributions (see Institutional Investor 2001). In addition, the importance of analyst perceptions of management quality to future performance probably explains why money managers value sell-side analysts' ability to organize events where they have the opportunity to meet and evaluate corporate executives privately or in small groups (Institutional Investor, 2001).

Note that estimates for analyst ratings of governance, strategy communication, superior product/service strategy, financial strength, and understanding of competitors are generally statistically insignificant and have weak economic effects. The finding on governance is particularly interesting

8Using only observations from analysts who provided usable responses for three companies, we re-estimated all the models. The results are very similar to those reported here. 
given the regulatory efforts to improve governance through the Sarbanes-Oxley Act of 2002. Several possible explanations come to mind. One is that analysts perceive little difference in governance across the companies they cover. Alternatively, judging which companies have effective governance may be difficult for analysts because outsiders cannot easily determine whether boards are actively debating critical management strategies and empowering internal and external auditors to assess whether risks are well managed.

Note also that strategy communication ratings are insignificant for buyside and sell-side analysts combined. These results, however, are driven by the results for buy-side analysts. In separate tests for sell-side analysts, we found that communication ratings are significantly related to forecasts of accounting and stock market performance. Buy-side analysts placed greater weight on the quality of top management in their forecasts of earnings growth and stock market performance than did sell-side analysts.

Given the high correlations among the independent variables, we examined whether multicollinearity is a concern by using a test developed by Belsley, Kuh, and Welsh (1980). The results indicate that multicollinearity is not a serious problem for our estimates.

Overall, the industry, management, and company factors explain roughly 12-17 percent of the variation in analyst forecasts. Given the importance of the constructs surveyed, this percentage reflects a rather low explanatory power. One possible reason is that considerable variation exists in the relative importance of factors across industries, and the failure to reflect that variation in the panel data affects the estimated coefficients and the models' explanatory power. To test for this possibility, we re-estimated the models across 10 industry groups by using Thomson Reuters Datastream's industry/sector specifications: information technology, general industrials, financials, cyclical services, cyclical consumer goods, basic industries, noncyclical services, noncyclical consumer goods, natural resources, and utilities. The average pseudo- $R^{2}$ for the earnings growth models is 21 percent, ranging from a low of 
12 percent for information technology and noncyclical services to a high of 34 percent for natural resources. These results represent a modest increase over the aggregate results.

Another possible explanation is variation in the relative importance of

factors across geographic regions. The average explanatory power, however, did not increase when we re-estimated the models across four regions: North America, Europe, Asia, and Latin America.

In summary, these results suggest that analyst forecasts of corporate performance are consistently related to their assessments of industry growth and competitiveness, leadership and cultural capabilities (leadership quality and performance-driven culture), company capabilities (strategy execution and innovation), and strategy choice (price competitiveness).

\section{Consistency of Analysts' Ratings within Companies.}

We next examined whether financial experts who cover the same company have common perceptions of its future performance, core qualitative capabilities, and industry dynamics. Much has been written about consistency among analysts' earnings forecasts (O’Brien 1988; Brown 1991). Factors that can lead to forecast consistency include analysts' ability to extrapolate from public historical information about a company, their ability to benchmark their forecasts with public forecasts issued by other analysts, and their incentives to herd (see Trueman 1994; Graham 1999; Hong, Kubik, and Solomon 2000; Clement and Tse 2005; Clarke and Subramanian 2006).

Such qualitative factors as industry dynamics, leadership, and company capabilities have also been proposed as relevant to company performance. As noted earlier, money managers view analysts' assessments of industry dynamics, companies' strategic positioning, and companies' internal capabilities as among their most important research contributions (see Institutional Investor 2001), which suggests that they believe analysts are able 
to identify company variations credibly. Yet little evidence on this matter exists. Is reliably measuring such factors straightforward or difficult for analysts?

To examine the consistency of analysts' ratings on our survey questions, we estimated intraclass correlation statistics for each question by using a company class variable. We computed the intraclass correlation (ICC) as follows:

$$
I C C=\frac{M S_{b f}-M S_{w f}}{M S_{b f}+(k-1) M S_{w f}},
$$

where $M S_{b f}$ is the mean squares between companies, $M S_{w f}$ is the mean squares within companies, and $k$ is the number of companies. ${ }^{9}$ The correlation measures the average consistency of the ratings of analysts who cover the same company and, in theory, can range from 1 (perfect consistency) to 0 (no consistency). Bliese (2000) noted that for applied field research, estimates of 0.05-0.20 are typical and estimates greater than 0.30 are unusual.

To calculate intraclass correlation coefficients, we included only companies with responses from at least two analysts in a sample year. 10 The usable sample comprised 784 company-years, for which the mean (median) coverage was four (three) analysts. ${ }^{11}$

Table 5 reports the weighted average intraclass correlations for both surveys, with the weights being the number of observations in each survey. The correlations range from 0.15 to 0.415 , which suggests considerable variation across survey questions in consistency among analysts covering the same company. The highest correlations are for forecasted revenue growth (0.415), balance sheet strength (0.414), strategy execution (0.382), and clear communication of strategy (0.345). The high correlations for balance sheet

\footnotetext{
${ }^{9}$ For an extensive discussion of statistics for inter-rater agreement, see Shrout and Fleiss (1979) and Fleiss (1981).

${ }^{10}$ We performed our analysis separately for each sample year (2005 and 2006) and then aggregated the results to allow for time-varying correlations.

${ }^{11}$ Including only companies covered by more than four analysts yielded similar results.
} 
strength and strategy communication are not surprising given that they reflect publicly available information. Strategy execution is also likely to be highly correlated with current performance. But why there is greater analyst consistency for forecasted revenues than for forecasted earnings or gross margins is unclear.

The correlations are lowest for industry competitiveness (0.15), forecasted stock appreciation (0.171), low-price strategy (0.195), and expected high standards (0.206). The low correlation for forecasted stock appreciation is not surprising. If markets are relatively efficient, considerable disagreement is likely over whether a stock is expected to increase or decrease in value, giving rise to inconsistent recommendation ratings and a low correlation. But the low correlations for low-price strategy and industry competitiveness are puzzling because strategies for many companies (e.g., Dell, Wal-Mart, Apple) and the competitiveness of their industries should be transparent to all analysts who cover them.

Note that buy-side analysts' assessments of companies' qualitative characteristics and future performance are significantly less consistent than sell-side analysts' assessments. The average intraclass correlation coefficient for buy-side analysts is 23 percent, compared with 34 percent for sell-side analysts. One explanation for this finding is that sell-side analysts face pressure to issue similar assessments to peers covering the same company. After all, one would be hard put to blame a sell-side analyst for issuing a rating that ends up losing money if others made the same mistake. In contrast, many buy-side analysts are encouraged to take positions in opposition to the sell side, leading to less consistency in their ratings (see Groysberg, Healy, and Chapman 2008).

To assess whether analysts are more likely to be consistent on financial forecasts than on company capabilities, we examined the average estimates for both categories. We found little evidence that analysts agree more on financial forecasts than on internal capabilities. The average correlation for performance 
forecasts is 28 percent ( 31.6 percent excluding the question on stock price forecast), versus 30.5 percent for the questions on internal capabilities (28 percent excluding the questions on balance sheet strength and communication). In contrast, the average correlations for the competitive factors and the company strategy estimates are somewhat lower: 22.1 percent and 24.5 percent, respectively.

In summary, our findings suggest that considerable variation in consistency exists among analysts who cover the same company for many of the variables surveyed. Not surprisingly, factors that reflect public information tend to have greater consistency. And sell-side analysts have greater consistency than buy-side analysts, perhaps reflecting their differing incentives. Consistency is relatively low, however, for questions on low-price strategy and industry competitiveness, which is troubling because both money managers and prior research suggest that those factors are important drivers of companies' future performance.

\section{Conclusion}

In our study, we used survey data to examine which industry, company, and leadership factors are related to analyst forecasts of company performance. Because many of the factors we surveyed are subjective, we also tested whether analysts who cover the same company make consistent assessments of those factors.

We found that many of the factors that money managers rate as important in their assessments of analyst contributions are strongly related to analyst forecasts of company performance. These include industry factors (notably, industry growth and competitiveness), leadership factors (top management quality), and company capabilities (in particular, strategy execution, innovation, and performance-driven culture). We found no evidence that analysts consider governance an important factor in their forecasts, despite recent regulatory changes and public focus. We suspect that despite 
the changes, assessing the quality of a company's board deliberations remains difficult for analysts. Finally, we detected systematic differences between buyside and sell-side analysts. Sell-side (but not buy-side) forecasts are related to strategy communication, and buy-side forecasts are related to management quality.

Considerable variation in ratings consistency exists among analysts who cover the same company. Factors with the highest consistency ratings include revenue forecasts, strategy execution, strategy communication, and balance sheet strength. Factors with the lowest consistency ratings include forecasted stock performance, industry competitiveness, and low-price strategy. We are puzzled by the fact that analysts who cover the same company show such little consistency in their ratings of industry competitiveness and low-price strategy; these factors would seem to be easily identifiable, at least for many companies. Consistency is significantly lower for buy-side analysts than for their sell-side peers, perhaps reflecting stronger sell-side incentives to herd. We found no evidence that analysts are more consistent on financial forecast factors (where they can use historical results and other analyst forecasts as benchmarks) than on internal capability factors (where no such benchmarks are readily available).

Despite the usual limitations of surveys, we believe our findings are likely to interest scholars, educators, and practitioners. Our findings confirm many predictions about the relevance for future performance of certain factors concerning industry dynamics, strategic choices, and company capabilities, and they underscore the importance of analysts' building a strong understanding of a company's industry and its qualitative capabilities. Acknowledgments

We gratefully acknowledge the Division of Research at Harvard Business School for funding this research. We thank Sarah Eriksen and John Sheridan for 
research assistance and Robert Kaplan, Linda-Eling Lee, and Mark Maletz for helpful comments. We also thank $I / B / E / S$ and First Call for analyst data.

Keywords: Equity Investments: Fundamental Analysis (Sector, Industry, Company) and the Valuation of Individual Equity Securities: Company Analysis; Portfolio Management: Economic Analysis and Capital Market Expectations: Macroeconomic Forecasts in Determining Asset Class/Security Return Expectations; Behavioral Finance: Institutional Investor Decision Making: Herding Behavior in Analyst Estimates

Author Online Summary

Although extensive research has been conducted on analysts' earnings forecasts and recommendations, relatively little has been written about the factors that underlie them. In our study, we examined which industry, leadership, and company factors are related to analysts' forecasts of financial and stock performance. We also examined whether analysts covering the same company make consistent assessments of its industry, leadership, and company capabilities.

To study these questions, we used data from a survey of 967 analysts who rated 837 companies on their projected future performance, industry economics, company capabilities, and leadership. Analysts were asked to provide forecasts of growth in revenues, earnings, and stock price, as well as gross margins, for up to three companies they covered. For each company, they were also asked to rate industry, company, and leadership factors that prior research suggests influence future performance. These factors include the competitiveness and growth of each company's industry, whether it competes primarily on the basis of innovation or price, its strategy execution and communication, its innovativeness, existing financial resources, the quality of its top management, whether management sets high performance standards, and its governance.

We found a strong relationship between analysts' forecasts of a company's performance and their assessments of its industry growth, industry competition, quality of its management, commitment to high performance 
expectations, ability to execute strategy, and innovation. We found that several factors are generally unimportant, including governance, transparent strategy communication (especially for buy-side analysts), competition via superior products/services, financial strength, and understanding one's competitors.

Considerable variation in ratings consistency exists across factors among analysts who cover the same company. Analyst ratings are relatively more consistent for company revenue forecasts, balance sheet strength, strategy execution, and strategy communication than for industry competitiveness, forecasted stock appreciation, low-price strategy, and understanding one's competitors. Consistency is significantly higher for sell-side analysts than for their buy-side peers, perhaps reflecting sell-side pressure to herd. Finally, we found no evidence that analysts are more consistent on financial forecast factors than on internal capability factors.

\section{References}

Abarbanell, J.S. 1991. "Do Analysts' Earnings Forecasts Incorporate Information in Prior Stock Price Changes?" Journal of Accounting and Economics, vol. 14, no. 2 (June):147-165.

Asquith, P., M.B. Mikhail, and A.S. Au. 2005. "Information Content of Equity Analyst Reports." Journal of Financial Economics, vol. 75, no. 2 (February):245282.

Bass, B.M. 2008. The Bass Handbook of Leadership: Theory, Research, and Managerial Applications. 4th ed. New York: The Free Press.

Belsley, D., E. Kuh, and E. Welsh. 1980. Regression Diagnostics: Identifying Influential Data and Sources of Collinearity. New York: John Wiley \& Sons.

Bliese, D. 2000. "Within-Group Agreement, Non-Independence, and Reliability: Implications for Data Aggregation and Analysis." In Multilevel Theory, Research, and Methods in Organizations: Foundations, Extensions, and New Directions. Edited by K.J. Klein and S.W. Kozlowski. San Francisco: Jossey-Bass.

Bower, J.L. 1970. Managing the Resource Allocation Process: A Study of Corporate Planning and Investment. Boston: Harvard Business School Press.

Brandenburger, A.M., and B.J. Nalebuff. 1996. Co-Opetition. New York: Currency Doubleday. 
Bradshaw, M. 2010. “Analysts' Forecasts: What Do We Know After Decades of Work?” Working paper, Boston College.

Brown, L.D. 1991. "Forecast Selection When All Forecasts Are Not Equally Recent." International Journal of Forecasting, vol. 7, no. 3 (November):349-356.

Campbell, J.Y., A.W. Lo, and A.C. MacKinlay. 1997. Econometrics of Financial Markets. Princeton, NJ: Princeton University Press.

Carter, C.B., and J.W. Lorsch. 2004. Back to the Drawing Board: Designing Corporate Boards for a Complex World. Boston: Harvard Business School Press.

Christensen, C.M. 1997. The Innovator's Dilemma: When New Technologies Cause Great Firms to Fail. Boston: Harvard Business School Press.

Clarke, J., and A. Subramanian. 2006. "Dynamic Forecasting Behavior by Analysts: Theory and Evidence." Journal of Financial Economics, vol. 80, no. 1 (April):81-113.

Clement, M.B., and S.Y. Tse. 2005. "Financial Analyst Characteristics and Herding Behavior in Forecasting." Journal of Finance, vol. 60, no. 1 (February):307-341.

Cowen, A., B. Groysberg, and P. Healy. 2006. "Which Types of Analyst Firms Are More Optimistic?" Journal of Accounting and Economics, vol. 41, no. 1-2 (April):119-146.

Daum, J. 2002. "Interview with Baruch Lev: Accounting, Reporting and Intangible Assets." New Economy Analyst Report (6 March): www.juergendaum.com/news/03_06_2002.htm.

Dugar, A., and S. Nathan. 1995. "The Effect of Investment Banking Relationships on Financial Analysts' Earnings Forecasts and Investment Recommendations." Contemporary Accounting Research, vol. 12, no. 1 (Fall):131-160.

Finkelstein, S., D.C. Hambrick, and A.A. Cannella, Jr. 2009. Strategic Leadership: Theory and Research on Executives, Top Management Teams, and Boards. New York: Oxford University Press.

Fleiss, J.L. 1981. Statistical Methods for Rates and Proportions. New York: John Wiley \& Sons.

Galbraith, J.R., and R.K. Kazanjian. 1986. Strategy Implementation: Structure, Systems, and Process. 2nd ed. St. Paul, MN: West Publishing Company. 
Givoly, D., and J. Lakonishok. 1979. "The Information Content of Financial Analysts' Forecasts of Earnings: Some Evidence on Semi-Strong Inefficiency." Journal of Accounting and Economics, vol. 1, no. 3 (December):165-185.

Graham, J.R. 1999. "Herding among Investment Newsletters: Theory and Evidence." Journal of Finance, vol. 54, no. 1 (February):237-268.

Groysberg, B., P. Healy, and C. Chapman. 2008. "Buy-Side vs. Sell-Side Analysts' Earnings Forecasts." Financial Analysts Journal, vol. 64, no. 4 (July/August):25-39.

Hackman, J.R., and R. Wageman. 1995. "Total Quality Management: Empirical, Conceptual, and Practical Issues." Administrative Science Quarterly, vol. 40, no. 2 (June):309-342.

Henderson, R.M., and K.B. Clark. 1990. "Architectural Innovation: The Reconfiguration of Existing Product Technologies and the Failure of Established Firms." Administrative Science Quarterly, vol. 35, no. 1 (March):930.

Hong, H., J. Kubik, and D. Solomon. 2000. "Security Analysts' Career Concerns and Herding of Earnings Forecasts." Rand Journal of Economics, vol. 31, no. 1:121-144.

Huselid, M.A. 1995. "The Impact of Human Resource Management Practices on Turnover, Productivity, and Corporate Financial Performance." Academy of Management Journal, vol. 38, no. 3 (June):635-672.

Institutional Investor. 2001. "The 2001 All-America Research Team." Institutional Investor (October):99-106.

Joyce, W.F., N. Nohria, and B. Roberson. 2003. What Really Works: The 4+2 Formula for Sustained Business Success. New York: Harper Business.

Kaplan, R.S., and D.P. Norton. 2008. The Execution Premium: Linking Strategy to Operations for Competitive Advantage. Boston: Harvard Business School Press.

Kaplan, S.N., M.M. Klebanov, and M. Sorensen. 2008. "Which CEO Characteristics and Abilities Matter?” NBER Working Paper 14195 (July).

Kaplowitz, M.D., T.D. Hadlock, and R. Levine. 2004. "A Comparison of Web and Mail Survey Response Rates.” Public Opinion Quarterly, vol. 68, no. 1 (March):94-101.

Kotter, J.P. 1990. A Force for Change: How Leadership Differs from Management. New York: The Free Press. 
Kotter, J.P., and J.L. Heskett. 1992. Corporate Culture and Performance. New York: The Free Press.

Lin, H., and M.F. McNichols. 1998. "Underwriting Relationships, Analysts' Earnings Forecasts and Investment Recommendations." Journal of Accounting and Economics, vol. 25, no. 1 (February):101-127.

Lys, T., and S. Sohn. 1990. "The Association between Revisions of Financial Analysts' Earnings Forecasts and Security-Price Changes." Journal of Accounting and Economics, vol. 13, no. 4 (December):341-363.

Mansfield, E. 1995. Innovation, Technology and the Economy: The Selected Essays of Edwin Mansfield. Brookfield, VT: Edward Elgar Publishing.

McGahan, A.M., and M.E. Porter. 1997. "How Much Does Industry Matter, Really?” Strategic Management Journal, vol. 18, no. S1 (July):15-30.

McNichols, M., and P.C. O'Brien. 1997. "Self-Selection and Analyst Coverage." Journal of Accounting Research, vol. 35 (Supplement):167-199.

Mowery, D.C., and N. Rosenberg. 1998. Paths of Innovation: Technological Change in 20th-Century America. Cambridge, U.K.: Cambridge University Press.

O’Brien, P.C. 1988. "Analysts' Forecasts as Earnings Expectations." Journal of Accounting and Economics, vol. 10, no. 1 (January):53-83.

Porter, M.E. 1980. Competitive Strategy: Techniques for Analyzing Industries and Companies. New York: The Free Press.

Porter, M.E. 1985. Competitive Advantage: Creating and Sustaining Superior Performance. New York: The Free Press.

Previts, G.J., R.J. Bricker, T.R. Robinson, and S.J. Young. 1994. "A Content Analysis of Sell-Side Financial Analyst Company Reports." Accounting Horizons, vol. 8, no. 2:55-70.

Ramnath, S., S. Rock, and P.B. Shane. 2008. "A Review of Research Related to Financial Analysts' Forecasts and Stock Recommendations." Working paper, University of Colorado at Boulder (30 June).

Rogers, R., and J. Grant. 1997. "Content Analysis of Information Cited in Reports of Sell-Side Financial Analysts." Journal of Financial Statement Analysis, vol. 3, no. 1 (Fall):17-30.

Schumpeter, J.A. 1942. Capitalism, Socialism and Democracy. New York: Harper \& Brothers. 
Schipper, K. 1991. "Commentary on Analysts' Forecasts." Accounting Horizons, vol. 5, no. 4:105-131.

Shrout, P.E., and J.L. Fleiss. 1979. "Intraclass Correlations: Uses in Assessing Rater Reliability.” Psychological Bulletin, vol. 86, no. 2 (March):420-428.

Trueman, B. 1994. "Analyst Forecasts and Herding Behavior." Review of Financial Studies, vol. 7, no. 1 (January):97-124.

Tushman, M.L., and C.A. O'Reilly. 2002. Winning through Innovation: A Practical Guide to Leading Organizational Change and Renewal. Boston: Harvard Business School Press.

Utterback, J.M. 1994. Mastering the Dynamics of Innovation: How Companies Can Seize Opportunities in the Face of Technological Change. Boston: Harvard Business School Press.

Wasserman, N., N. Nohria, and B. Anand. 2010. "When Does Leadership Matter? A Contingent Opportunities View of CEO Leadership." In Handbook of Leadership and Theory Practice. Edited by Nitin Nohria and Rakesh Khurana. Boston: Harvard Business School Publishing. 
Exhibit 1. Analyst Survey Questions

\begin{tabular}{llc}
\hline $\begin{array}{l}\text { Question } \\
\text { No. }\end{array}$ & Question & Variable \\
& & Name \\
\hline & $\begin{array}{c}\text { Industry performance } \\
\text { In the next } 12 \text { months, how likely are the following in each company's } \\
\text { business environment: }\end{array}$ & IG \\
1 & a. Demand growth greater than GDP growth? & ICOMP $^{\mathrm{a}}$ \\
3 & b. Greater price competition? & ICOMP $^{\mathrm{a}}$ \\
5 & c. Higher input prices? & ICOMP $^{\mathrm{a}}$
\end{tabular}

Financial performance and investment prospects

Relative to its peers, how do you expect the company to perform during the next 12 months on the following dimensions:

b. Gross margin? $\quad$ FGM

c. Earnings growth? FEG

d. Stock price appreciation? $\quad$ FSG

Company strategy

10 Relative to its peers, does the company have a clear and well-communicated SCLR strategy?

Relative to its peers, how compelling is the company's value proposition for its customers on each of these dimensions:

11

12

13

Qualitative capabilities

14 Relative to its peers, how well does the company operationalize and execute against its strategy?

15 Relative to its peers, how often is the company at the leading edge of innovation in its industry?

17

18

19

Relative to its peers, how strong is the company's top management team?

LPR

DIFF $^{b}$

DIFF $^{\mathrm{b}}$
SEXEC

INNOV

MGT

GOV

COMP

PSTD
Relative to its peers, how demanding are the performance standards of the company?

Financial resources

$20 \quad$ Relative to its peers, how strong is the company's balance sheet?

FSTR

'Industry competitiveness (ICOMP) is an analyst's average rating for Questions 2-5.

${ }^{\mathrm{b}}$ Superior products/services strategy (DIFF) is an analyst's maximum rating for Questions 12 and 13. 
Table 1. Summary of Survey Responses by Geographic Region and Industry

\begin{tabular}{lccccc} 
& \multicolumn{2}{c}{ Observations } & & \multicolumn{2}{c}{ Companies } \\
\cline { 2 - 3 } \cline { 5 - 6 } & Number & $\begin{array}{c}\text { Percentage of } \\
\text { Sample }\end{array}$ & & Number & $\begin{array}{c}\text { Percentage of } \\
\text { Sample }\end{array}$ \\
\hline Geographic region & & & & & \\
United States & 1,170 & $53.7 \%$ & & 356 & $42.5 \%$ \\
Europe & 598 & 27.4 & & 234 & 28.0 \\
Asia Pacific & 330 & 15.1 & & 192 & 22.9 \\
Latin America & $\underline{81}$ & $\underline{3.7}$ & & $\underline{55}$ & $\underline{6.6}$ \\
$\quad$ Total & 2,179 & $100.0 \%$ & & 837 & $100.0 \%$ \\
& & & &
\end{tabular}

\section{Industries}

Basic industries

124

$5.7 \%$

61

$7.3 \%$

Cyclical consumer goods

98

4.5

4.5

Cyclical services

272

12.5

38

13.1

Financials

543

24.9

189

22.6

General industrials

137

6.3

61

7.3

Information technology

394

18.1

101

12.1

Noncyclical consumer goods

328

15.1

126

15.1

Noncyclical services

140

6.4

62

7.4

Natural resources

78

3.3

49

5.9

Utilities

$\underline{65}$

Total

2,179

3.0

$\underline{40}$

$\underline{4.8}$

$100.0 \%$

837

$100.0 \%$

Note: The sample comprises 2,179 responses for 837 companies by 967 analysts surveyed between December 2004 and April 2005 and between March 2006 and July 2006. 
Table 2. Frequency Statistics for Dependent and Independent Variables

\begin{tabular}{llllll}
\hline & \multicolumn{5}{c}{ Percentage of Responses Rated As } \\
Variable & \multicolumn{1}{c}{1} & \multicolumn{7}{c}{2} & 3 & \multicolumn{1}{c}{4} & 5 \\
\hline Forecasted revenue growth (FRG) & $4.1 \%$ & $14.4 \%$ & $28.9 \%$ & $36.6 \%$ & $16.0 \%$ \\
Forecasted gross margin (FGM) & 2.0 & 13.9 & 35.5 & 36.3 & 12.3 \\
Forecasted earnings growth (FEG) & 2.9 & 12.4 & 29.1 & 38.8 & 16.8 \\
Forecasted stock appreciation (FSG) & 3.6 & 13.8 & 31.3 & 36.4 & 15.0 \\
Clear, well-communicated strategy (SCLR) & 3.8 & 12.7 & 22.7 & 34.4 & 26.6 \\
Ability to execute strategy (STRATEX) & 3.1 & 10.9 & 25.0 & 38.2 & 22.8 \\
Governance strength (GOV) & 4.9 & 11.8 & 36.2 & 31.3 & 15.8 \\
Quality of top management (MGT) & 1.8 & 11.0 & 28.0 & 38.2 & 21.0 \\
Innovation leader (INNOV) & 3.7 & 11.9 & 29.2 & 35.7 & 19.5 \\
Low-price strategy (LPR) & 9.1 & 22.8 & 42.2 & 17.8 & 8.2 \\
Superior products/services strategy (DIFF) & 0.8 & 4.8 & 24.3 & 41.0 & 29.1 \\
Balance sheet strength (FSTR) & 3.5 & 9.0 & 24.3 & 29.7 & 33.4 \\
High performance standards (PSTD) & 2.8 & 13.1 & 42.8 & 34.0 & 7.3 \\
Understands competitors (COMP) & 1.6 & 7.6 & 28.9 & 38.9 & 23.0 \\
Forecasted industry growth (IG) & 3.8 & 12.1 & 25.6 & 33.8 & 24.8 \\
Industry competitiveness (ICOMP) & 1.6 & 22.3 & 52.0 & 22.0 & 2.1 \\
\hline
\end{tabular}

Notes: Industry growth (IG) is the rating to the question whether industry demand is expected to grow faster than GDP growth (Question 1). Industry competitiveness (ICOMP) is the analyst's average rating for Questions 2-5, which deal with whether the analyst expects higher price competition, higher input prices, and increased threats from new products and/or competitors in the next 12 months. Strategic clarity (SCLR) is the rating for Question 10, which asks the analyst whether the company has a clear strategy that is well communicated. The two strategic positioning variables are LPR, representing the rating for Question 11 (whether the company's value proposition is low prices), and DIFF, which is the analyst's maximum rating for Questions 12 and 13 (whether the company's value proposition is superior products/services). Strategy execution (STRATEX) is the rating for Question 14, which asks the analyst to assess how well a company executes its strategy. Innovation (INNOV) is the analyst's rating for Question 15, which asks how often the company is at the leading edge of innovation in its industry. Note that innovation includes both process and product/service innovation and is thus not merely another proxy for company strategy. MGT is the analyst's rating of the quality of top management (Question 16). Governance (GOV) is captured by the rating for Question 17 (the quality of the company's governance). Understanding one's competitors (COMP) is captured by the rating for Question 18 (the company's understanding of the strengths and weaknesses of its competitors). High performance standards (PSTD) is captured by the rating for Question 19 (the extent to which the company's performance standards are demanding). Financial strength (FSTR) is captured by Question 20 (the strength of the company's balance sheet). 
Table 3. Pearson Correlations between Survey Responses

\begin{tabular}{|c|c|c|c|c|c|c|c|c|c|c|c|c|c|c|c|}
\hline Variable & FRG & FGM & FEG & FSG & SCLR & STRATEX & GOV & MGT & INNOV & LPR & DIFF & FSTR & PSTD & COMP & IG \\
\hline Forecasted revenue growth (FRG) & 1.00 & & & & & & & & & & & & & & \\
\hline Forecasted gross margin (FGM) & 0.54 & 1.00 & & & & & & & & & & & & & \\
\hline Forecasted earnings growth (FEG) & 0.65 & 0.57 & 1.00 & & & & & & & & & & & & \\
\hline Forecasted stock appreciation (FSG) & 0.51 & 0.46 & 0.59 & 1.00 & & & & & & & & & & & \\
\hline Clear, well-communicated strategy (SCLR) & 0.42 & 0.37 & 0.38 & 0.35 & 1.00 & & & & & & & & & & \\
\hline Ability to execute strategy (STRATEX) & 0.50 & 0.42 & 0.45 & 0.39 & 0.64 & 1.00 & & & & & & & & & \\
\hline Governance strength (GOV) & 0.26 & 0.27 & 0.28 & 0.27 & 0.44 & 0.43 & 1.00 & & & & & & & & \\
\hline Quality of top management (MGT) & 0.45 & 0.42 & 0.44 & 0.40 & 0.58 & 0.64 & 0.51 & 1.00 & & & & & & & \\
\hline Innovation leader (INNOV) & 0.40 & 0.33 & 0.35 & 0.31 & 0.43 & 0.46 & 0.33 & 0.47 & 1.00 & & & & & & \\
\hline Low-price strategy (LPR) & 0.12 & 0.06 & 0.11 & 0.12 & 0.06 & 0.10 & 0.05 & 0.05 & -0.02 & 1.00 & & & & & \\
\hline Superior products/services strategy (DIFF) & 0.34 & 0.32 & 0.31 & 0.28 & 0.42 & 0.45 & 0.33 & 0.43 & 0.48 & -0.04 & 1.00 & & & & \\
\hline Balance sheet strength (FSTR) & 0.28 & 0.32 & 0.27 & 0.26 & 0.36 & 0.41 & 0.36 & 0.42 & 0.30 & -0.01 & 0.32 & 1.00 & & & \\
\hline High performance standards (PSTD) & 0.43 & 0.40 & 0.39 & 0.33 & 0.55 & 0.61 & 0.49 & 0.59 & 0.51 & 0.07 & 0.43 & 0.35 & 1.00 & & \\
\hline Understands competitors (COMP) & 0.42 & 0.37 & 0.37 & 0.32 & 0.54 & 0.58 & 0.40 & 0.56 & 0.45 & 0.09 & 0.41 & 0.35 & 0.54 & 1.00 & \\
\hline Forecasted industry growth (IG) & 0.41 & 0.33 & 0.35 & 0.31 & 0.24 & 0.30 & 0.19 & 0.27 & 0.27 & 0.03 & 0.28 & 0.24 & 0.26 & 0.24 & 1.00 \\
\hline Industry competitiveness (ICOMP) & -0.12 & -0.08 & -0.09 & -0.08 & -0.05 & -0.06 & -0.03 & -0.04 & -0.02 & -0.01 & 0.02 & -0.04 & 0.01 & -0.06 & -0.04 \\
\hline
\end{tabular}

Notes: The reported Pearson correlations (based on ratings) are virtually identical to Spearman (rank) correlations. Correlations greater than 0.05 or less than -0.05 are significantly different from zero at the 1 percent level. 
Table 4. Relationship between Analysts' Forecasts of Company Performance and Their Ratings of Industry Factors, Company Strategy, and Company Capabilities

\begin{tabular}{|c|c|c|c|c|c|c|c|c|}
\hline & \multicolumn{4}{|c|}{ Results without Control for Current Performance } & \multicolumn{4}{|c|}{ Results with Control for Current Performance } \\
\hline & Revenue Growth & Gross Margin & Earnings Growth & Stock Growth & Revenue Growth & Gross Margin & Earnings Growth & Stock Growth \\
\hline $\begin{array}{l}\text { Clear, well-communicated strategy } \\
\text { (SCLR) }\end{array}$ & $0.075^{*}$ & 0.048 & 0.047 & $0.077^{* *}$ & 0.061 & $0.078^{*}$ & 0.057 & $0.075^{*}$ \\
\hline Ability to execute strategy (STRATEX) & $0.212 * *$ & $0.096^{*}$ & $0.180 * *$ & $0.113^{* *}$ & $0.183^{* *}$ & $0.135^{* *}$ & $0.166^{* *}$ & $0.094 *$ \\
\hline Governance strength (GOV) & -0.070 & -0.020 & -0.010 & 0.016 & $-0.100 * *$ & -0.050 & -0.030 & 0.017 \\
\hline Quality of top management (MGT) & $0.141 * *$ & $0.152 * *$ & $0.201 * *$ & $0.199 * *$ & $0.141^{* *}$ & $0.138 * *$ & $0.204 * *$ & $0.182^{* *}$ \\
\hline $\begin{array}{l}\text { Low-price strategy (LPR) } \\
\text { Superior products/services strategy }\end{array}$ & $0.109^{* *}$ & 0.033 & $0.097 * *$ & $0.105^{* *}$ & $0.110^{* *}$ & 0.048 & $0.097 * *$ & $0.107 * *$ \\
\hline (DIFF) & 0.048 & $0.083^{*}$ & 0.041 & 0.043 & 0.073 & 0.072 & 0.059 & 0.044 \\
\hline Balance sheet strength (FSTR) & 0.016 & $0.111 * *$ & 0.019 & 0.041 & 0.006 & $0.078^{*}$ & 0.008 & 0.033 \\
\hline High performance standards (PSTD) & $0.142 * *$ & $0.163 * *$ & $0.099 * *$ & 0.027 & $0.149^{* *}$ & $0.155^{* *}$ & $0.116^{*}$ & 0.034 \\
\hline Understands competitors (COMP) & $0.105^{*}$ & $0.091 *$ & 0.049 & 0.012 & $0.121 * *$ & 0.084 & 0.045 & 0.008 \\
\hline Forecasted industry growth (IG) & $0.301 * *$ & $0.206^{* *}$ & $0.230 * *$ & $0.184^{* *}$ & $0.287^{* *}$ & $0.184 * *$ & $0.236^{* *}$ & $0.180^{* *}$ \\
\hline Current performance & & & & & $0.937 * *$ & $0.003^{*}$ & 0.002 & $0.288 * *$ \\
\hline Pseudo- $R^{2}$ & $16.54 \%$ & $12.49 \%$ & $13.22 \%$ & $9.92 \%$ & $16.77 \%$ & $12.55 \%$ & $13.28 \%$ & $9.82 \%$ \\
\hline Number of observations & 2,162 & 2,126 & 2,170 & 2,137 & 1,965 & 1,499 & 1,812 & 1,964 \\
\hline
\end{tabular}




\section{Table 5. Intraclass Correlation Statistics for Analyst Agreement on} Company Characteristics

\begin{tabular}{ll} 
Variable & $\begin{array}{c}\text { Average Intraclass } \\
\text { Correlation }\end{array}$ \\
\hline Forecasts & \\
Forecasted revenue growth (FRG) & $41.5 \%$ \\
Forecasted gross margin (FGM) & 24.9 \\
Forecasted earnings growth (FEG) & 28.4 \\
Forecasted stock appreciation (FSG) & $\underline{17.1}$ \\
$\quad$ Average & $28.0 \%$ \\
& \\
Competitive factors & \\
Forecasted industry growth (IG) & $29.1 \%$ \\
Industry competitiveness (ICOMP) & 15.0 \\
$\quad$ Average & $22.1 \%$ \\
& \\
Company strategy & \\
Low-price strategy (LPR) & $19.5 \%$ \\
Superior products/services strategy (DIFF) & $\underline{29.5}$ \\
$\quad$ Average & $24.5 \%$ \\
Internal capabilities & \\
Clear, well-communicated strategy (SCLR) & \\
Ability to execute strategy (STRATEX) & $34.5 \%$ \\
Innovation leader (INNOV) & 38.2 \\
Quality of top management (MGT) & 31.0 \\
Governance strength (GOV) & 24.1 \\
Balance sheet strength (FSTR) & 28.0 \\
Understands competitors (COMP) & 41.4 \\
High performance standards (PSTD) & 20.6 \\
$\quad$ Average & $\underline{25.8}$ \\
Comparison of buy-side and sell-side analysts & $30.4 \%$ \\
Buy-side analysts & \\
Sell-side analysts & $23.1 \%$ \\
\hline
\end{tabular}

Notes: We computed the intraclass correlation coefficient for every question in the survey. We included all companies that were ranked by at least two analysts to ensure variation both within and between companies. Average correlations are weighted averages of the estimates for the 2004-05 and 2006 surveys, weighted by the number of observations in each survey. 